\title{
A Binary Distillation Column Top and Bottom Compositions Control Using Two PI Controllers Tuned with SIMC
}

\author{
ALINA SIMONA BAIESU*, MADALINA CARBUREANU* \\ Petroleum-Gas University of Ploiesti, Automatic Control, Computers and Electronics Department, 39 Bucuresti Blvd., \\ 100680, Ploiesti, Romania
}

\begin{abstract}
The opportunity analysis of using two Proportional-Integral (PI) controllers, tuned with Skogestad's variant of Simple Internal Model Control based (SIMC) method, for controlling the top and bottom compositions of a propylene/propane distillation column represents the paper aim. The SIMC method for PID controllers is the simplest and extremely good model in tuning procedures. Because the distillation process is nonlinear, the process model is described by a reunion of different linear models, for the different process operating ranges and, for each operating range, different sets of controllers' tuning parameters are computed using SIMC tuning method. In order to validate the experimental results a comparison is made with the case when the PI controllers are tuned using Ziegler-Nichols (ZN) method that uses the step response and process approximation exactly as Skogestad's variant of SIMC.
\end{abstract}

\section{Keywords: PID controller, PID tuning methods, Skogestad Simple Internal Model Control, propylene/propane distillation column}

This paper goal is to present a good and simple method for controlling the top and bottom compositions of a binary distillation column using two Proportional-Integral controllers.

The paper continues the author's studies for top and bottom compositions control at propylene/propane distillation column. Initially, the control solution considered for this process was using model based control algorithms, such Model Predictive Control [1] or Internal Model Control [2]. The results obtained were good, but the computing and implementation effort were substantially. Then, the solution was to use the oldest, the simplest and easy to implement control algorithm, namely PID, with its particular PI form.

In order to obtain the best control system efficiency there are a great variety of tuning methods. These methods can be divided into classical and optimization methods.

The classical tuning methods named Internal Model Control (IMC) based PID tuning (IMC-PID), with its variant - Skogestad's SIMC, use formulas based on the process model parameter values (gain, time constants and dead time) [3]. Other classical tuning methods such ZieglerNichols (Z-N), can use formulas based on some tuning parameter values that bring the process to its limit of stability [4].

The optimization tuning methods based on Neural Networks (NN) [5], Genetic Algorithms (GA) [6] or Differential Evolution (DE) [7] relies on the optimization of a function such Integral of Absolute magnitude Error (IAE), Integral of the Squared Error (ISE), Mean of the Squared Error (MSE) or Integral of Time multiplied by Absolute Error (ITAE).

Due to the wide variety of the tuning methods [8], the tuning method using Genetic Algorithms was presented in one of our study [9]. The results were good, but the computing effort is extremely high. In this paper it considers the solution of tuning the PI control algorithm using SIMC (Skogestad Simple Internal Model Control).

The SIMC tuning method uses the classical PID tuning ideas presented by Ziegler and Nichols [4], the IMC-PID tuning results from [3], and the tuning rules presented by Smith and Corripio [10]. Ziegler-Nichols tuning method

\footnotetext{
* email: agutu@upg-ploiesti.ro, mcarbureanu@upg-ploiesti.ro
}

offers poor efficiency for processes with dominant delay [11]. Also, the IMC-PID tuning from [3] gives poor disturbance response for integrating processes [12], but is a robust one and offers good responses for setpoint changes. The SIMC tuning rule works well for both integrating and pure time delay processes, for setpoints and disturbances changes [13].

Considering the paper goal, to control the top and bottom compositions of a nonlinear binary distillation column using a simple control algorithm (PI) using simple and powerful methods (ZN and SIMC), the contributions can be summarized as follows:

-The nonlinear process was linearized, being approximated by first order lag with dead time transfer functions, having different constants according to the process operating point;

-The SIMC and ZN controller tuning methods were implemented in order to find the PI controllers tuning parameter values; these values adapts to the process operating range;

-The proposed control system was tested with respect to setpoint and disturbance step change and the simulation results were compared between the two tuning methods that were used;

-Because the control system response to setpoint step change has a small overshoot in case of using SIMC and a large overshoot in case of using ZN, in order to obtain a better dynamic response, having a smaller overshoot, a first order lag prefilter with its time constant being equal to the inverse of the zero of the closed-loop transfer function was used, in the setpoint value path.

\section{PI controller tuning}

The Proportional-Integral-Derivative (PID) control algorithm is described by the following time domain equation:

$$
c(t)=c_{0}(t)+k_{R} \cdot\left(e(t)+\frac{1}{T_{i}} \int_{0}^{t} e(t) d t+T_{d} \frac{d e}{d t}\right),
$$

where $c(t)$ is the controller output, $c_{0}(t)$ - the initial controller output value, $\mathrm{e}(\mathrm{t})$ - the error value, which is the difference between the desired process output value (setpoint) and 
the actual output value, $\mathrm{k}_{\mathrm{B}}$ - the controller gain; $\mathrm{T}_{i}$-the integral time constant and $T_{d}$ is the derivative time constant [14].

The PID controller transfer function is:

$$
G_{\mathrm{P} I D}(s)=k_{\Omega} \cdot\left(1+\frac{1}{T_{i} \cdot s}+T_{d} \cdot s\right) .
$$

The PI algorithm, which is a particular form of PID algorithm, can be obtained by setting the derivative time constant from equations ( 1 ) or (2) equal to zero $\left(T_{d}=0\right)$. This algorithm was used for the study considered in this paper.

Industrial processes are nonlinear, with different gains and settling times, depending on the process operating range and channel. In order to use an efficient control algorithm, it must be able to consider the process nonlinearities. A way to do this is to describe the process model by a reunion of linear models for the different process operating ranges and channels, and in case of using the $\mathrm{PI}$ control algorithm, for example, different sets of tuning parameter values to be considered, according to the process operating range.

Tuning a PI (Proportional-Integral) controller using Skogestad Simple Internal Model Control (SIMC) method

The IMC-Based PID control design procedure is a general control design method which is based on the Internal Model Control concept and structure [3]:

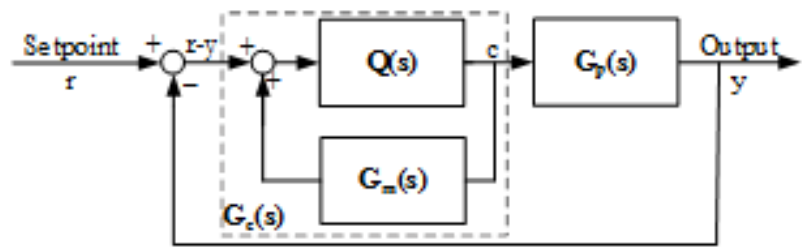

Fig. 1. The IMC structure

In figure $1, Q(s)$ is the primary IMC controller transfer function, $G_{C}(s)$ - the IMC controller transfer function, $r$ setpoint, c -controller's output, y - process output, $G_{m}(s)$ the process model transfer function and $G_{p}(s)$ - the process transfer function.

From the IMC equivalentstructure (fig. 2) and the closedloop control general structure (fig. 3), we have:

$$
G_{P I D}(s)=G_{c}(s) \text {. }
$$

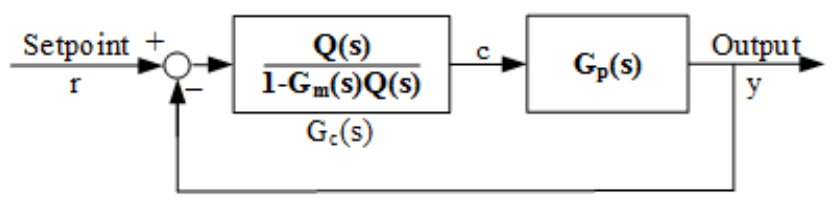

Fig. 2. The IMC equivalent structure

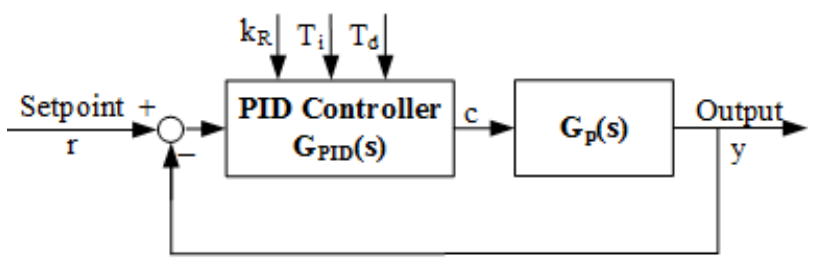

Fig. 3. A control system closed-loop structure

If the process model is represented as a first order with time delay transfer function

$$
G_{m}(s)=\frac{k_{m} \cdot e^{-s}}{T_{m} \cdot s+1},
$$

the primary IMC controller transfer function is:

$$
Q(s)=\frac{\left(T_{m} \cdot s+1\right)}{k_{m} \cdot\left(T_{c} \cdot s+1\right)},
$$

and

$$
G_{c}(s)=\frac{T_{m}}{k_{m} \cdot\left(T_{c}+\tau\right)} \cdot \frac{T_{m} \cdot s+1}{T_{m} \cdot s},
$$

where $k_{m}$ is the process model gain, $T_{m}$ is the process model time constant, $\tau$ is the time delay and $T$ is a filter time constant. The filter is considered in order to obtain a semiproper and not improper transfer function for $\mathrm{Q}(\mathrm{s})$.

The values for the process model parameters from (4) $\left(k_{m}, T_{m}\right.$ and $\left.\tau\right)$ can be easily found from the process step response (fig.4) [13].

In figure 4, $u$ is the system input variable with the steadystate value $\alpha, y$-system output variable with the steadystate value $\beta, T_{\text {st }}$-settling time: the time until system output reaches $98 \%$ from, $\beta, T_{\text {p }}$ - the time until system output reaches $63 \%$ from $\beta$, $\tau$-time delay.

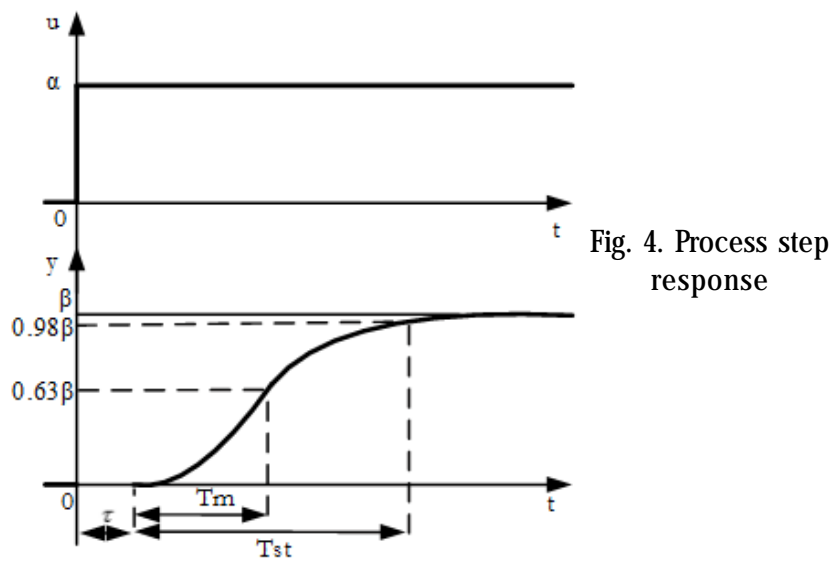

Approximating the process model time delay as

$$
e^{-s}=1-\tau \cdot s,
$$

and considering $T_{d}=0$, we have:

$$
G_{P I}(s)=k_{R} \cdot \frac{T_{i} \cdot s+1}{T_{i} \cdot s} .
$$

From (3) the PI tuning parameters, $k_{R}$ and $T_{i}$ will be:

$$
\begin{aligned}
& k_{R}=\frac{1}{k_{m}} \cdot \frac{T_{m}}{T_{c}+\tau}, \\
& T_{i}=\min \left(T_{m}, 4 \cdot\left(T_{c}+\tau\right)\right) .
\end{aligned}
$$

$T$ it is considered as tuning parameter.

The main limitation on achieving a fast closed-loop response is the time delay $(\tau)$. Selecting the desired response time equal to the time delay,

$$
T_{\varepsilon}=\tau \text {, }
$$

gives a reasonably fast response with moderate input usage and good robustness margins [13].

\section{Tuning a PI (Proportional-Integral) controller using Ziegler- Nichols (ZN) method}

The Ziegler-Nichols (ZN) tuning method gives the controller tuning parameters $\mathrm{k}_{R}$ and $\mathrm{T}$ using equations (12) and (13) based on two parameters that characterize the process dynamics, which can be easily determined experimentally, the controller critical gain $\left(k_{f}\right)$ and the oscillations period of the controller output $(P)[4]$.

In order to find the two parameters the controller has only the proportional term, with a small controller gain $\left(k_{R}\right)$ and with $\mathrm{T}_{\mathrm{i}}=\infty$ and $\mathrm{T}_{\mathrm{d}}=0$. Then, the gain $\left(\mathrm{k}_{\mathrm{R}}\right)$ is increased until the loop oscillates for a setpoint step change, with 
constantamplitude. This controller gain value is the critical gain $\left(k_{R}=k_{C}\right)$. The oscillations period of the controller output $(P)$ must be recorded and the controller tuning parameters $\left(k_{R}^{C}\right.$ and $\left.T_{j}\right)$, are computed based on $k_{c}$ and $P_{c}$ values, according to formulas:

$$
\begin{aligned}
& k_{R}=\frac{k_{c}}{2.2}, \\
& T_{i}=\frac{P_{c}}{1.2} .
\end{aligned}
$$

In this paper, in order to control the top and bottom compositions of a propylene/propane distillation column, two PI controllers tuned using Skogestad Simple Internal Model Control (SIMC) will be used. The results will be compared with the ones that can be obtained in case of using Ziegler-Nichols (ZN) tuning method that uses the step response and process approximation with the first order lag with dead time, exactly as SIMC.

\section{Propylene-propane distillation column}

The binary distillation column (fig. 5) uses the L-B control strategy, as the reflux flow is used to control the top product (propylene) composition and the bottom product flow is used to control the bottom product (propane) composition [15].

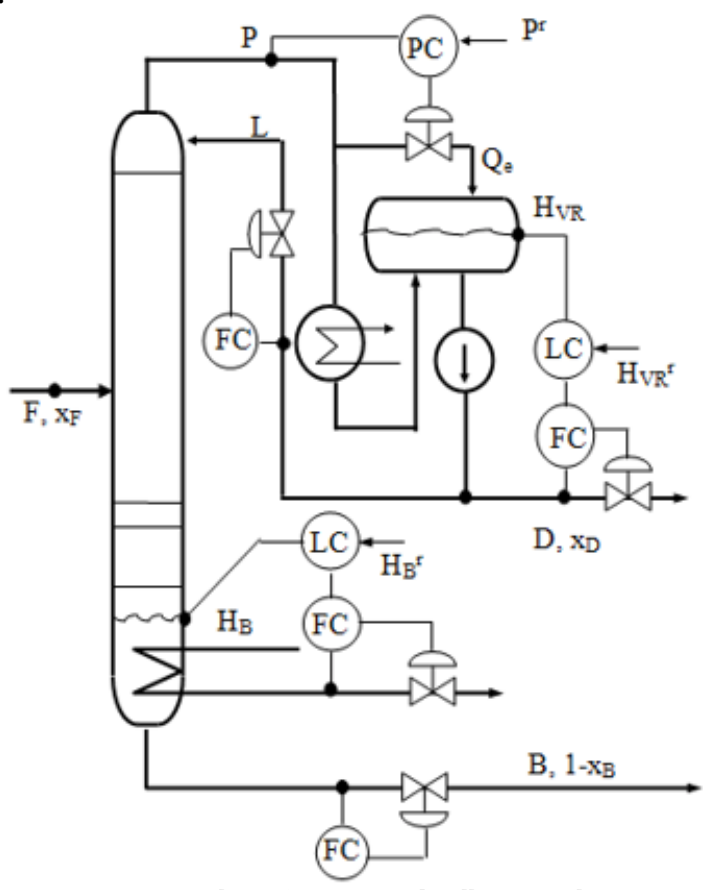

Fig. 5. Propylene / propane distillation column

In figure 5, PC, FC and LC are pressure, flow and level controllers, $L$ is the reflux flow, $P$ - pressure, $p^{r}$-pressure setpoint, $B$-bottom product flow, $\mathrm{H}_{V R}$-reflux tank level, $\mathrm{H}_{V R}{ }^{r}$ -reflux tank level setpoint, $H_{B}$-bottom column level, $H_{B}^{V_{B}}$ bottom column level setpoint, $F$-feed flow, $X_{F}$-feed composition, 1- $x_{B}$-bottom product propane composition and $x_{p}$ is the top product propylene composition.

The considered process block diagram is presented in figure 6 . The process has two outputs (the top/propylene and bottom/propane compositions), two control variables (the reflux and bottom product flows) and two disturbances (the feed flow and feed composition).

The process was previous simulated with HYSYS $^{\circledR}$ simulation environment, observing that it has a nonlinear behavior, characterized by different gains and settling times for different operating ranges and process channels (fig. 6, tables 1 and 2 [16].

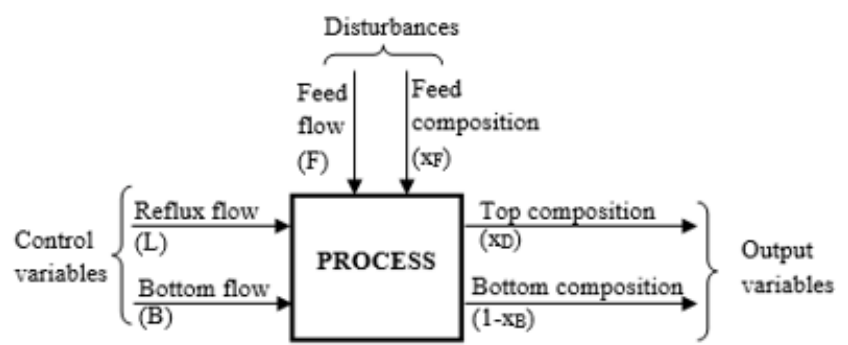

Fig. 6. Distillation process block diagram

The procedure of obtaining the process parameters $\left(k_{m}\right.$ and $T_{m}$ ) using the process step response, from tables 1 and 2 , was presented in detail in a previous paper [16].

Table 1

PROCESS GAIN $\left(k_{m}\right)$, SETTLING TIME $\left(T_{\mathrm{s}}\right)$ AND TIME CONSTANT $\left(T_{m}\right)$ VALUES FOR L- $x_{D}$ PROCESS CHANNEL, WITH THE OPERATING RANGE

\begin{tabular}{|l|l|l|l|}
\hline $\mathbf{x}_{\mathrm{D}}$ [mol.fr.] & $\mathrm{k}_{\mathrm{m}}$ & $\mathrm{T}_{\mathrm{st}}[\mathrm{min}]$ & $\mathrm{T}_{\mathrm{m}}[\mathrm{min}]$ \\
\hline $0.88-0.90$ & 0.65 & 105.6 & 26.4 \\
\hline $0.90-0.92$ & 0.53 & 102.0 & 25.5 \\
\hline $0.92-0.94$ & 0.39 & 98.1 & 24.5 \\
\hline $0.94-0.96$ & 0.33 & 95.0 & 23.8 \\
\hline $0.96-0.98$ & 0.30 & 92.8 & 23.2 \\
\hline $0.98-1.00$ & 0.28 & 88.1 & 22.0 \\
\hline
\end{tabular}

$\mathrm{x}_{\mathrm{D}}$ is the propylene molar fraction in the top of

the distillation column

Table 2

PROCESS GAIN $\left(k_{m}\right)$, SETTLING TIME $\left(T_{\mathrm{s}}\right)$ AND TIME CONSTANT $\left(T_{m}\right)$ VALUES FOR B-( $\left(1-x_{B}\right)$ PROCESS CHANNEL, WITH THE OPERATING RANGE

\begin{tabular}{|l|l|l|l|}
\hline $1-\mathrm{x}_{\mathrm{B}}$ [mol.fr.] & $\mathrm{K}_{\mathrm{m}}$ & $\mathrm{T}_{\mathrm{st}}[\mathrm{min}]$ & $\mathrm{T}_{\mathrm{m}}[\mathrm{min}]$ \\
\hline $0.88-0.90$ & -0.78 & 330.0 & 82.5 \\
\hline $0.90-0.92$ & -0.98 & 563.2 & 140.8 \\
\hline $0.92-0.94$ & -1.04 & 627.5 & 156.9 \\
\hline $0.94-0.96$ & -1.10 & 692.8 & 173.2 \\
\hline $0.96-0.98$ & -1.14 & 712.0 & 178.0 \\
\hline $0.98-1.00$ & -1.20 & 822.2 & 205.6 \\
\hline
\end{tabular}

$\mathrm{x}_{\mathrm{B}}$ is the propylene molar fraction and 1- $\mathrm{x}_{\mathrm{B}}$ is the

propane molar fraction in the bottom of the distillation column

A possible way to express the process model, for the two channels $L-x_{D}$ and $B-\left(1-x_{B}\right)$, is by a first order transfer function with dead time:

$$
G_{m}(s)=\frac{k_{m} \cdot e^{-s}}{T_{m} \cdot s+1},
$$

where $k_{m}$ is the process gain, $\tau$ is the time delay (dead time) and $T_{m}$ is the time constant- the time until the system output reaches $68 \%$ from its steady-state value [13]. The time delay is 3 min for $L-X_{D}$ process channel and 5 min for $\mathrm{B}-\left(1-\mathrm{X}_{\mathrm{B}}\right)$ process channel.

The parameters of the process model $\left(k_{m}, \tau\right.$ and $\left.T_{m}\right)$, which appear in (14), have different values according to 
the process operating range and process channel, according to tables 1 and 2 .

\section{Results and discussions}

The top and bottom compositions of the propylene/ propane distillation column (fig. 5) will be controlled using two PI controllers.

The nonlinear process was linearized for the two main channels, $L-X_{D}$ and $B-\left(1-X_{B}\right)$, and for different operating ranges, see relation (14) and tables 1 and 2. The two PI algorithms will have different sets of tuning parameters according to the process operating range, and will be computed using SIMC and ZN tuning methods.

The proposed control system structure is presented in figure 7.

In figure $7, x_{1}$ is the top product propylene composition, $\mathrm{X}_{\mathrm{D}}{ }^{\mathrm{r}}$ - top composition setpoint, $1-\mathrm{x}_{\mathrm{B}}$-bottom product propane composition, $\left(1-x_{B}\right)^{r}$ - bottom composition setpoint, L- reflux flow, B-bottom product flow, $L^{r}$-reflux flow setpoint and $B^{r}$ is the bottom product flow setpoint.

The two PI controllers tuning parameter values $\left(k_{\mathrm{B}}\right.$ and $T_{\text {. }}$ ), were found using Skogestad Simple Internal Model Control (SIMC) method presented above, using equations (9) and (10).

The procedure was applied for every process operating range from tables 1 and 2 .

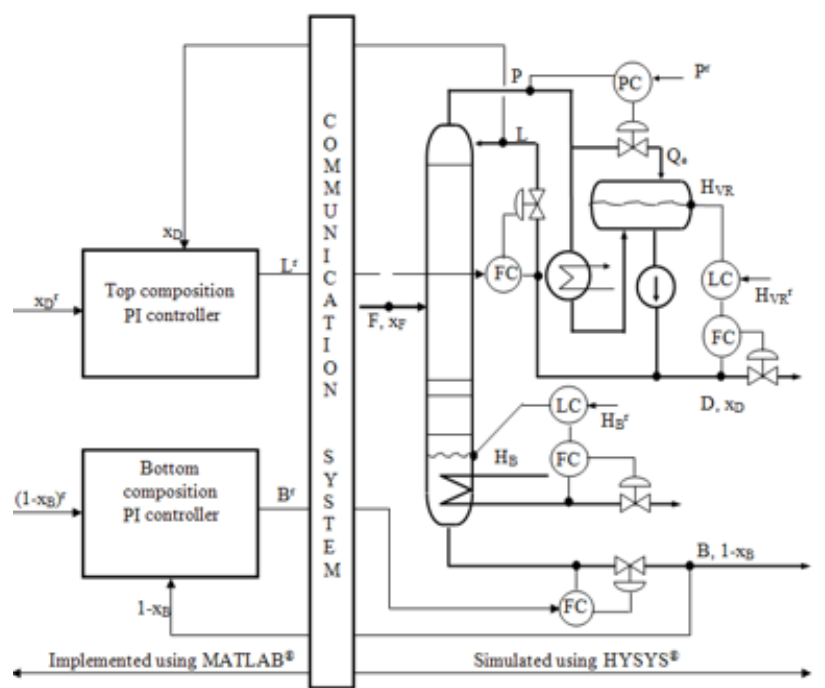

Fig. 7. The proposed control system structure

The obtained tuning parameter values are presented in tables 3 and 4.

The control system (the two PI controllers) was implemented in $M A T L A B^{\circledR}$, the tuning method, using Skogestad Simple Internal Model Control, was

Table 3

TUNING PARAMETER VALUES FOR THE TOP COMPOSITION PI CONTROLLER, WITH THE PROCESS OPERATING RANGE

\begin{tabular}{|c|c|c|c|c|}
\hline \multirow[t]{2}{*}{$\mathbf{x}_{\mathbf{D}}{ }^{*}$ [mol.fr.] } & \multicolumn{2}{|c|}{$\begin{array}{l}\text { Skogestad (SIMC) tuning } \\
\text { method }\end{array}$} & \multicolumn{2}{|c|}{$\begin{array}{l}\text { Ziegler-Nichols }(\mathrm{ZN}) \\
\text { tuning method }\end{array}$} \\
\hline & $\mathrm{k}_{\mathbb{R}}$ & $T_{i}[\min ]$ & $\mathrm{k}_{\mathrm{R}}$ & $T_{i}[\min ]$ \\
\hline $0.880-0.900$ & 6.8 & 26.4 & 10.3 & 9.65 \\
\hline $0.901-0.920$ & 8.0 & 25.5 & 12.2 & 9.64 \\
\hline $0.921-0.940$ & 10.5 & 24.5 & 15.9 & 9.62 \\
\hline $0.941-0.960$ & 12.0 & 23.8 & 18.3 & 9.60 \\
\hline $0.961-0.980$ & 12.9 & 23.2 & 19.6 & 9.59 \\
\hline $0.981-1.000$ & 13.1 & 22.0 & 20.0 & 9.57 \\
\hline
\end{tabular}

$\mathrm{x}_{\mathrm{D}}$ is the propylene molar fraction in the top of the distillation column

Table 4

TUNING PARAMETER VALUES FOR THE BOTTOM COMPOSITION PI CONTROLLER, WITH THE PROCESS OPERATING RANGE.

\begin{tabular}{|l|l|l|l|l|}
\hline \multirow{2}{*}{$\mathbf{l}^{*} \mathbf{x}_{\mathrm{B}}{ }^{*}$ [mol.fr.] } & \multicolumn{3}{|l|}{$\begin{array}{l}\text { Skogestad (SIMC) } \\
\text { tuning method }\end{array}$} & \multicolumn{2}{l|}{$\begin{array}{l}\text { Ziegler-Nichols (ZN) } \\
\text { tuning method }\end{array}$} \\
\cline { 2 - 5 } & $\mathrm{k}_{\mathrm{R}}$ & $\mathrm{T}_{\mathrm{i}}[\mathrm{min}]$ & $\mathrm{k}_{\mathrm{R}}$ & $\mathrm{T}_{\mathrm{i}}[\mathrm{min}]$ \\
\hline $\mathbf{0 . 8 8 0 - 0 . 9 0 0}$ & -10.6 & 82.5 & -15.7 & 16.4 \\
\hline $0.901-0.920$ & -14.4 & 140.8 & -21.2 & 16.5 \\
\hline $0.921-0.940$ & -15.1 & 156.9 & -22.2 & 16.6 \\
\hline $0.941-0.960$ & -15.7 & 173.2 & -23.1 & 16.6 \\
\hline $0.961-0.980$ & -15.8 & 178.0 & -23.9 & 16.6 \\
\hline $0.981-1.000$ & -17.1 & 205.6 & -25.1 & 16.6 \\
\hline
\end{tabular}

$\mathrm{x}_{\mathrm{B}}$ is the propylene molar fraction and 1- $\mathrm{x}_{\mathrm{B}}$ is the propane molar fraction in the bottom of the 

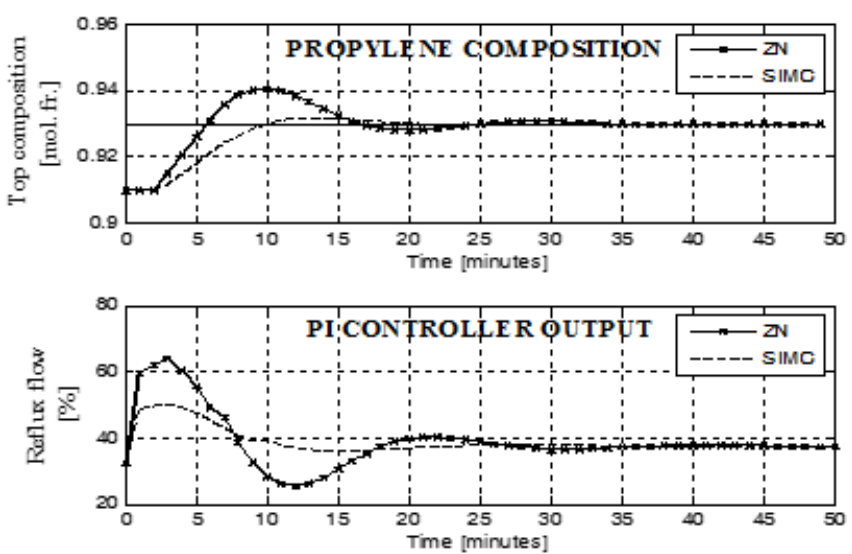

Fig. 8. Top composition trend when the PI controller setpoint increases from $0.91 \mathrm{~mol}$. fr. to $0.93 \mathrm{~mol}$. fr., using Skogestad (SIMC) tuning method $\left(\mathrm{k}_{\mathrm{R}}=8.0, \mathrm{~T}_{\mathrm{i}}=25.5 \mathrm{~min}, \mathrm{k}_{\mathrm{R}}=10.5, \mathrm{~T}_{\mathrm{S}}=24.5 \mathrm{~min}\right)$ and ZN tuning method $\left(k_{R}=12.2, T_{i}=9.64 \mathrm{~min}, k_{R}=15.9, T_{i}=9.62 \mathrm{~min}\right)$

implemented also in $M A T L A B^{\circledR}$ and the process was simulated in $\mathrm{HYSYS}^{\circledR}$

A feature of the $\mathrm{HYSYS}^{\circledR}$ simulator is the presence of the DDE (Dynamic Data Exchange) driver that can be used to communicate with other environment, such EXCEL or $M A T L A B^{\circledR}$, using the DDE protocol.

There are two synchronous DDE data communications that can be set between $\mathrm{HYSYS}^{\circledR}$ and MATLAB ${ }^{\circledR}$ :

- DDE communication based on client label;

- DDE communication based on the transmission of strings.

The second variant was implemented for this study, in order to link the two environments $\left(\mathrm{HYSYS}^{\circledR}\right.$ and $M A T L A B^{\circledR}$ ).

In tables 3 and 4 appear also the values of the tuning parameters obtained using ZN method, using (12) and (13).

The two PI controllers tuning parameters once computed using SIMC and ZN were saved for each operating range and, in real operation, each time a process operating range is changed the adequate $\mathrm{PI}$ tuning parameter values are loaded in the controller, according to tables 3 and 4.

The process nonlinearities are considered, as for the different process operating ranges we will have different PI tuning parameter values.

The proposed control system was tested for step changes in the top and bottom composition setpoints. The results obtained using SIMC tuning method were compared in terms of static and dynamic efficiency with the ones obtained if ZN tuning method is used.

From figure 8 we observe that in case of using SIMC, the top (propylene) composition becomes equal with its setpoint with good static (no offset) and dynamic efficiency (with a small settling time and negligible overshoot). In case of using ZN we have large output overshoot and a settling time bigger than in the case of using SIMC.

When the top (propylene) composition controller setpoint is changed so that the process output pass through three operating ranges (fig. 9, table 3) we also obtain a good static and dynamic efficiency of the control system response, better in case of using SIMC, than ZN.

In case of using a standard PI controller, with tuning parameters that do not adapt to the process nonlinearities, we obtain the results from figure 10 .

As we can observe from figure 10, the control system settling time increases substantially, in comparison with the case presented in figure 9 .

In this case, was considered that the tuning parameter values are the ones found using SIMC for the first operating
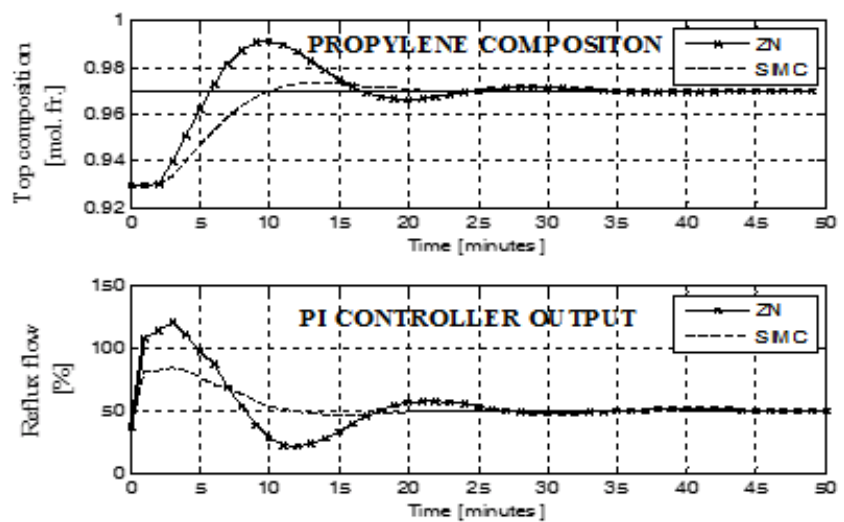

Fig. 9. Top composition trend when the PI controller setpoint increases from $0.93 \mathrm{~mol}$. fr. to $0.97 \mathrm{~mol}$. fr., using Skogestad (SIMC) tuning method $\left(\mathrm{k}_{\mathrm{R}}=10.5, \mathrm{~T}_{\mathrm{i}}=24.5 \mathrm{~min}, \mathrm{k}_{\mathrm{R}}=12.0, \mathrm{~T}_{\mathrm{i}}=23.8 \mathrm{~min}, \mathrm{k}_{\mathrm{R}}\right.$ $\left.=12.9, T_{i}=23.2 \mathrm{~min}\right)$ and $Z \mathrm{~N}$ tuning method $\left(\mathrm{K}_{\mathrm{R}}=15.9, \mathrm{~T}_{\mathrm{i}}=9.62 \mathrm{~min}\right.$ $k_{R}=18.3, T_{i}=9.6 \min , k_{R}=19.60, T_{i}=9.59 \mathrm{~min}$ )
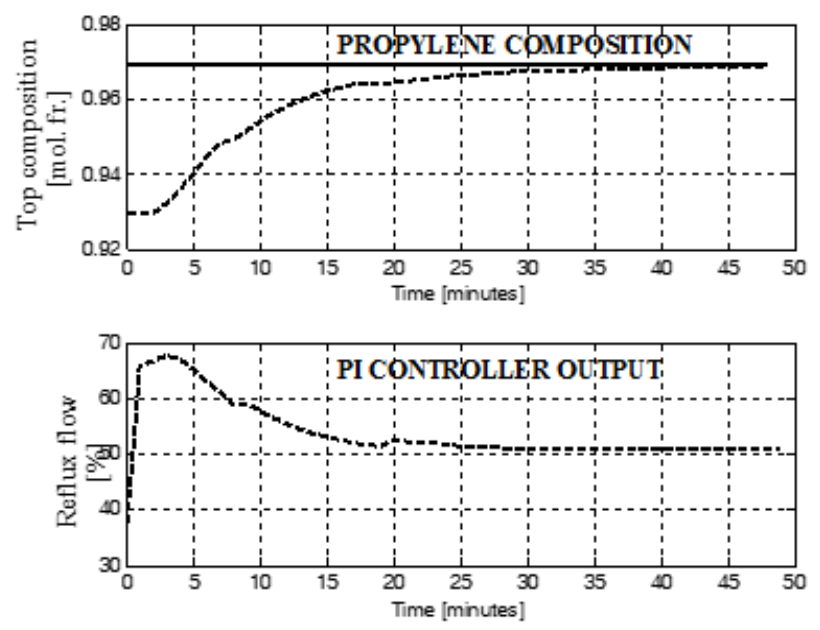

Fig. 10. Top composition trend when the PI controller setpoint increases from $0.93 \mathrm{~mol}$. fr. to $0.97 \mathrm{~mol}$. fr., using a standard PI controller with tuning parameters that do not adapt to the process operating range, using SIMC tuning method $\left(\mathrm{k}_{\mathrm{R}}=6.8, \mathrm{~T}_{\mathrm{i}}=26.4 \mathrm{~min}\right)$

range considered (table 3), namely $k_{R}=6.8$ and $T_{i}=26.4$ min.

The tests were made also for the bottom (propane) composition control loop.

From figure 11 we can observe that using SIMC tuning method for the proposed bottom (propane) composition
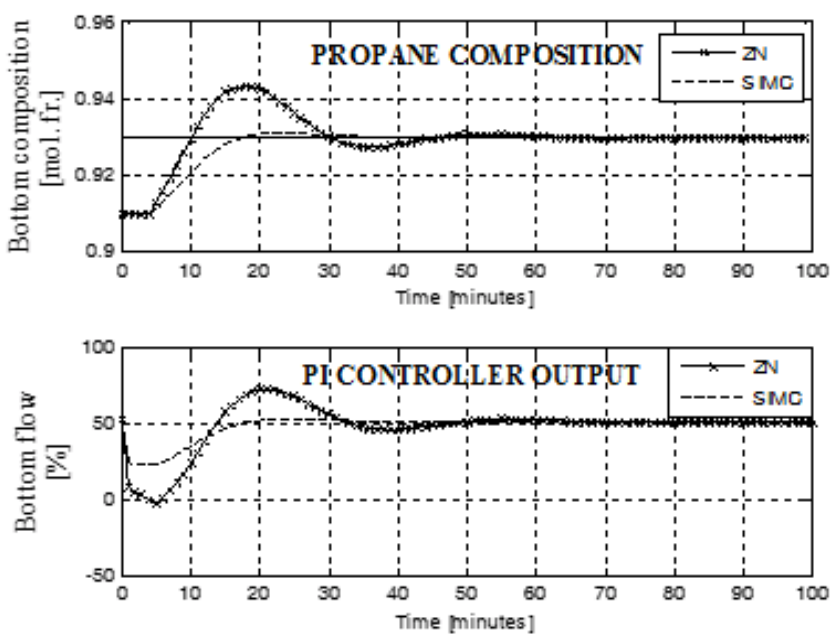

Fig. 11. Bottom composition trend when the PI controller setpoint increases from $0.91 \mathrm{~mol}$. fr. to $0.93 \mathrm{~mol}$. fr., using Skogestad (SIMC) tuning method $\left(k_{R}=-14.4, T_{i}=140.8 \mathrm{~min}, k_{R}=-15.1, T_{i}=156.9 \mathrm{~min}\right)$ and ZN tuning method $\left(k_{R}=-21.2, T_{i}=16.5 \mathrm{~min}, k_{R}=-22.2, T_{i}=16.6 \mathrm{~min}\right)$. 
PI controller we obtain better control system dynamic efficiency, than in the case of using ZN.

In case of changing the bottom (propane) composition controller setpoint so that the process output pass through three operating ranges (fig. 12) the PI controller adapts to the process nonlinearities, (table 4).
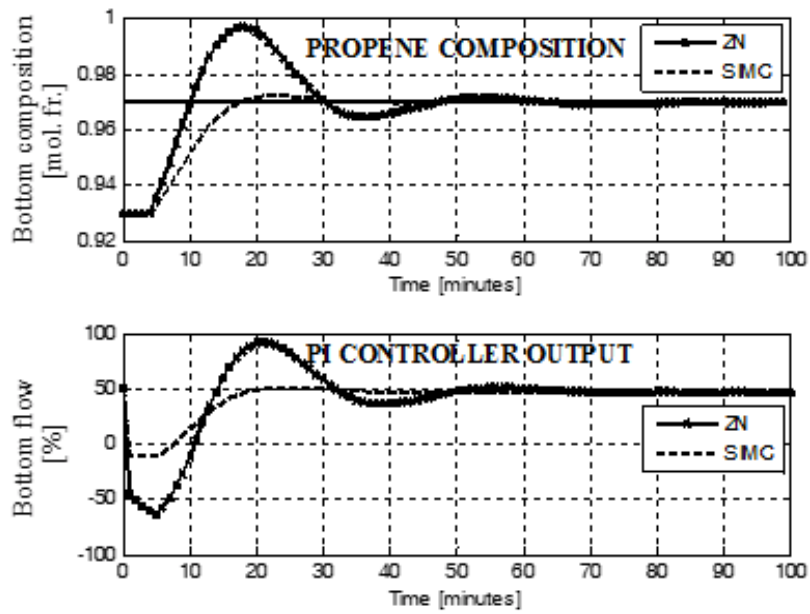

Fig. 12. Bottom composition trend when the PI controller setpoint increases from $0.93 \mathrm{~mol}$. fr. to $0.97 \mathrm{~mol}$. fr., using Skogestad (SIMC) tuning method $\left(k_{R}=-15.1, T_{i}=156.9 \mathrm{~min}, k_{R}=-15.7, T_{i}=173.2 \mathrm{~min}\right.$, $\left.k_{R}=-15.8, T_{i}=178.0 \mathrm{~min}\right)$ and $Z \mathrm{~N}$ tuning method $\left(k_{R}=-22.2, T_{i}=16.6\right.$ $\min , k_{R}=-23.1, T_{i}=16.6 \min , k_{R}=-23.9, T_{i}=16.6 \mathrm{~min}$ ).

In case of using a standard PI controller with tuning parameters that do not adapt to the process nonlinearities, as infigure 13, we can observe that the control system settling time increases substantially, in comparison with the case presented in figure 12 .
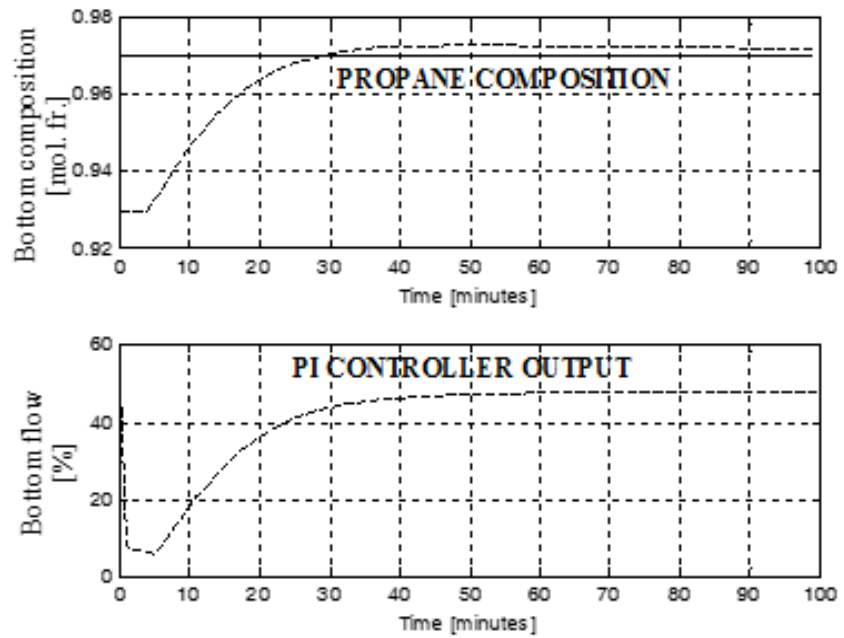

Fig. 13. Bottom composition trend when the controller setpoint increases from $0.93 \mathrm{~mol}$. fr. to $0.97 \mathrm{~mol}$. fr., using a standard PI controller with tuning parameters that do not adapt to the process operating range, using SIMC tuning method

$$
\left(k_{R}=-10.6, T_{i}=82.5 \mathrm{~min}\right)
$$

In this case, the tuning parameter values are the ones found using SIMC for the first considered operating range (table 4), namely $\mathrm{k}_{\mathrm{R}}=-10.6$ and $\mathrm{T}_{\text {. }}=82.5 \mathrm{~min}$.

In order to get a better insight, the two controllers were tested also in case of disturbances (feed flow (F) and feed composition $\left(\mathrm{x}_{\mathrm{f}}\right)$ ) step change.

The results are presented in figures 14-17. Here are presented the process response and the control system response to a disturbance increase of $5 \%$, in case of using SIMC and ZN tuning methods.

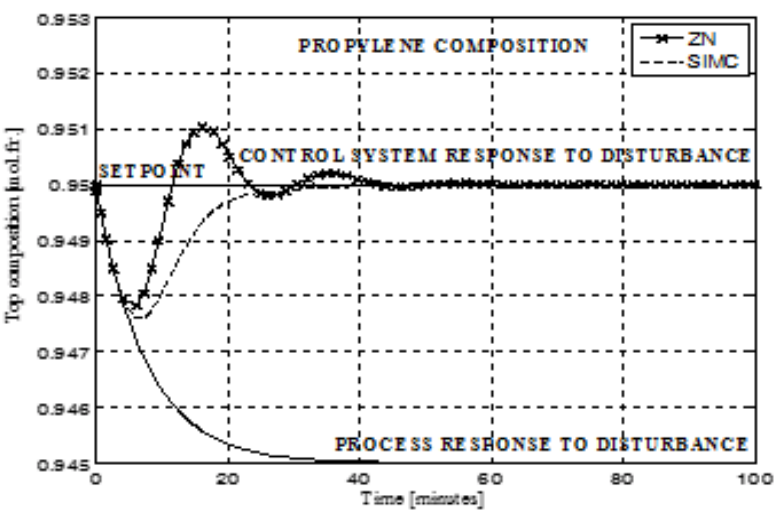

Fig. 14. Top composition trend when the feed flow (F) increases with $5 \%$.

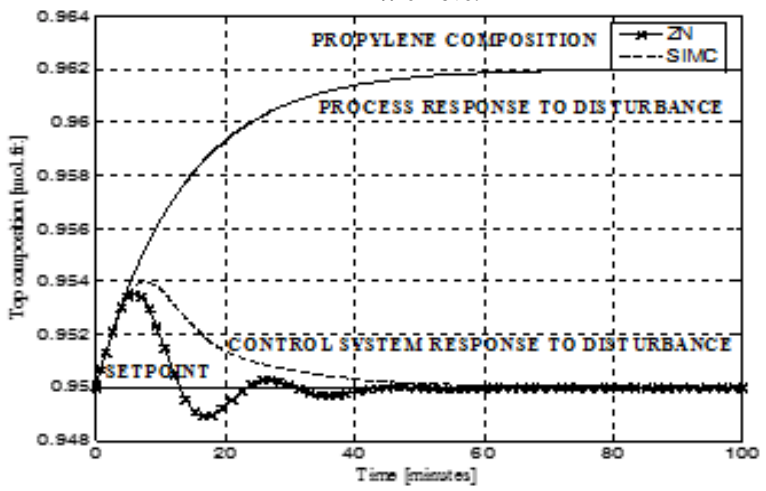

Fig. 15. Top composition trend when the feed composition $\left(x_{F}\right)$ increases with $5 \%$.

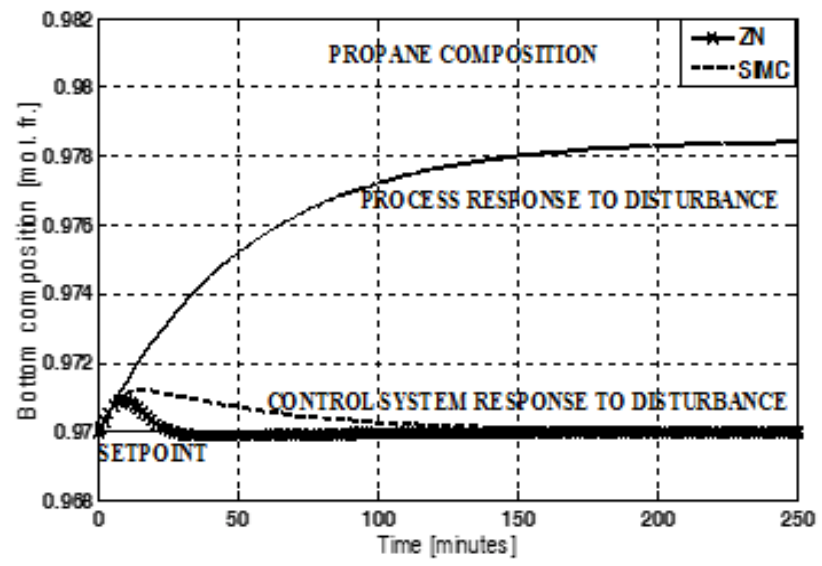

Fig. 16. Bottom composition trend when the feed flow (F) increases with $5 \%$.

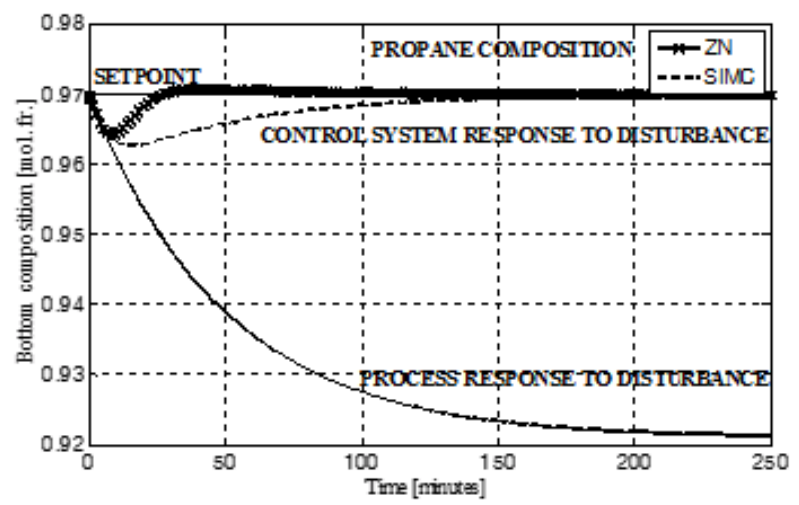

Fig. 17. Bottom composition trend when the feed composition $\left(x_{F}\right)$ increases with $5 \%$

The simulation results show that the SIMC and ZN tuning methods offer also a good response in case of disturbance step change. 
In order to obtain an even better dynamic response to setpoint step changes, in both studied cases (PI controllers tuned with SIMC and ZN, respectively), a first order lag prefilter was implemented in the setpoint path, having the time constant equal to the inverse of the zero of the closedloop transfer function. This is done in order to reduce the control system response overshoot.

The prefilter time constant should be also adapted to the process operating range.

The simulation results are presented in figure 18 and figure 19.

As we can see from figure 18 and 19 when the prefilter is used, in comparison with figure 9 and 12 , when there is no prefilter, the control system overshoot is reduced, obtaining an even better dynamic response in both studied cases (PI controllers tuned with SIMC and ZN).

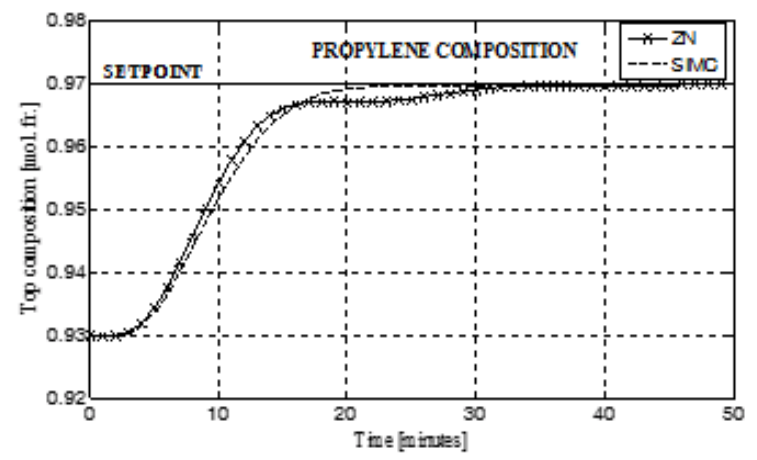

Fig. 18. Top composition trend when the PI controller setpoint increases from $0.93 \mathrm{~mol}$. fr. to $0.97 \mathrm{~mol}$. fr., using SIMC and ZN tuning methods and a first order lag prefilter in the setpoint path

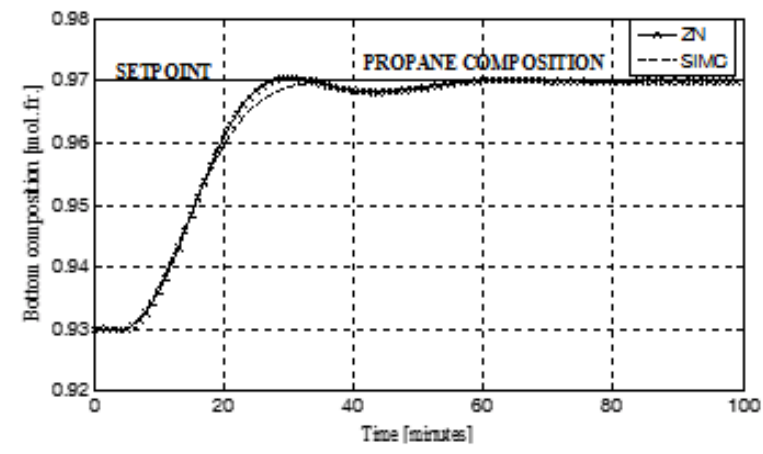

Fig. 19. Bottom composition trend when the PI controller setpoint increases from $0.93 \mathrm{~mol}$. fr. to $0.97 \mathrm{~mol}$. fr., using SIMC and ZN tuning methods and a first order lag prefilter in the setpoint path

As we can observe form the above presented results, when the SIMC tuning method it is used we obtain better control system efficiency characterized by smaller settling times, controlled output overshoots and controller output efforts.

The SIMC tuning method has also the advantage of being extremely simple, easy to implement and having a computing effort that is smaller even in comparison with ZN method.

\section{Conclusions}

This paper presents the results of controlling the top and bottom compositions of a propylene/propane distillation column using tw o PI controllers tuned with the Skogestad
Simple Internal Model Control (SIMC) tuning method. Because the process is a nonlinear one, was considered the case of PI controllers that use different sets of controller tuning parameter values, computed according to the process operating range.

The results were compared with the ones obtained when the ZN tuning method is also used for the two PI controllers.

It was showed that in case of using the SIMC method for tuning the PI controllers we obtain better control systems dynamic efficiency in terms of settling times, output overshoots, control effortand consumed power than in case of using ZN.

The case of PI controllers that have tuning parameters which do not adapt to the process nonlinearities and have fixed values equal to the ones computed for the first operating ranges, was also considered. In this case, the control systems dynamic efficiency is worse, characterized by a substantial increase in the control systems settling times.

Also, the simplicity of the SIMC tuning method must be mentioned as a big advantage.

\section{References}

1.PARASCHIV N., BAIESU A., STAMATESCU G., IEEE International Conference on Control and Automation, Christchurch, New Zealand, E-ISBN 978-1-4244-4707-7, PRINT ISBN 978-1-4244-4706-0 DOI: 10.1109/ ICCA.2009.5410331, 2009, p. 581.

2.BAIESU A., PARASCHIV N., MIHAESCU D., IEEE International Conference on Mechatronics and Automation Beijing, China, ISBN: 978-1-4244-8151-4, DOI: 10.1109/ICMA.2011.5986231, 2011, p 1588.

3.RIVERA D.E., MORARI M., SKOGESTAD S., Ind. Eng. Chem. Res. 25(1), 1986, p. 252.

4.ZIEGLER J.G., NICHOLS N.B., Trans. ASME, Vol. 64, 1942. p. 759.

5.DOLEZEL P., MARES J ., ASR 2009 Instruments and Control, 2009, p. 33.

6.SALAMI M., CAIN G., IEE Genetic Algorithms in Engineering Systems, Innovations and Applications Conference, Publication No. 414, 1995. 7.GAO F., TONG H., Proc. of the International Conference on Complex Systems and Applications, 2006, p. 785.

8.BANSAL H., SHARMA R., SHREERAMAN P. R., J ournal of Control Engineering and Technology, Vol. 2(4), 2012, p. 168.

9.BAIESU A., Binary distillation column top and bottom compositions control using two PI controllers tuned with GA", Proceedings The 9h IEEE International Conference on Intelligent Data Acquisition and Advanced Computing Systems: Technology and Applications, Bucharest, Romania, ISBN 978-1-5386-0696-4, 2017, p. 537.

10.SMITH C.A., CORRIPIO A.B., Principles and Practice of Automatic Process Control, John Wiley \& Sons, 1985.

11.TYREUS B.D., LUYBEN W.L., Ind. Eng. Chem. Res., 1992 p. 2628. 12.HORN I.G., ARULANDU J.R., GOMBAS J., VANANTWERP J.G., BRAATZ R.D., Ind. Eng. Chem. Res. 35(10), 1996, p. 3437.

13.SKOGESTAD S., J ournal of Process Control, Vol. 13(4), 2003 p. 291. 14.BAIESU A., Tehnica Reglarii Automate, Editura Matrix Rom, Bucuresti, 2012.

15.SHINSKEY F. G., Distillation Control, 2nd Edition. McGraw-Hill, 1984.

16.BAIESU, A., Rev. Chim. (Bucharest), 64, no. 4, 2013, p. 445.

Manuscript received: 21.03 .2018 